\title{
El Branded Content en la era de la comunicación posdigital [Reseña]
}

\section{Branded Content in the era of post-digital communication [Review]}

Fechas | En edición: 07/12/2021 - Publicación final: 01/01/2022

\section{Dra. Eglee ORTEGA-FERNÁNDEZ}

Universidad Antonio de Nebrija. España. eortegafe@nebrija.es. https://orcid.org/0000-0001-7103-2403

\section{El Branded Content en la comunicación posdigital: estructuras, aplicaciones y casos de éxito}

Coordinadores: J. OLIVARES-SANTAMARINA; R- GAGO-GELADO

Madrid: Tirant lo Blanch, 2021

311 páginas

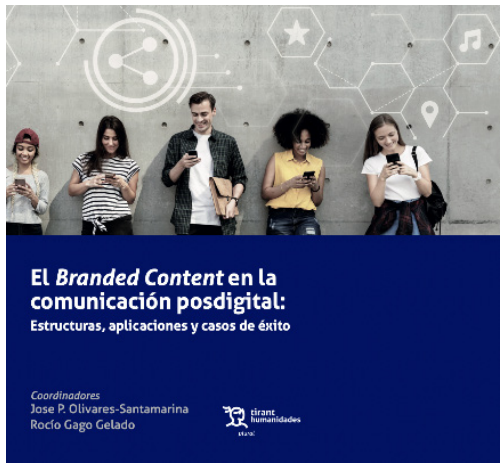

ISBN: 978-84-18534-04-1

\section{Resumen}

El libro "El Branded Content en la comunicación posdigital: estructuras, aplicaciones y casos de éxito" plantea una visión integral que busca consolidar la conexión entre la universidad y la empresa, generando una propuesta para definir en qué consiste exactamente esta estrategia desde diferentes visiones, a fin de entender sus principales objetivos y el papel que cumple en la estructura del trabajo de los anunciantes. Gracias a las colaboraciones entre académicos y profesionales se expresan en cada capítulo, investigaciones en la era de la comunicación posdigital que animan, tanto a estudiantes como a responsables de marca, a entender el branded content como una estrategia de comunicación eficaz que contempla nuevas fórmulas adaptadas a una audiencia que ha evolucionado.

\section{Palabras clave}

Branded Content; comunicación eficaz; creación de contenidos; marcas; posdigital.

\begin{abstract}
The book "Branded Content in post-digital communication: structures, applications and success stories" proposes an integral vision that seeks to consolidate the connection between the university and the company, generating a proposal to define what exactly this strategy consists of from different perspectives, to understand its main objectives and the role it plays in the structure of the advertisers' work. Thanks to the collaborations between academics and professionals, research in the era of post-digital communication is expressed in each chapter that encourages both students and brand managers to understand branded content as an effective communication strategy that includes new adapted formulas to an audience that has evolved.
\end{abstract}

\section{Keywords}

Branded Content; efficient communication; content creation; brands; postdigital 
El informe de Infoadex (2021), sobre el Estudio de la Inversión Publicitaria en España en 2020, apunta que los medios estimados, anteriormente llamados no convencionales, representaron el $54,8 \%$ de la inversión total en nuestro país. De este porcentaje el Branded Content se posiciona en quinto lugar por su volumen sobre el total, y supone el $6,1 \%$ de la cifra de los medios estimados. Su cifra de inversión en 2020 ha aumentado un 1,6\%, hasta situarse en los 363,7 millones de euros.

Tomando en cuenta el interés de los medios por esta estrategia, aunado la calificación que "la publicidad menos intrusiva" que se deriva del I Estudio de Branded Content, presentado por el IAB (2021), la universidad y la empresa se han unido en investigaciones que destacan la relevancia de esta comunicación activa que es producida o coproducida por una marca y que tiene como propósito conectarse con la audiencia desde sus valores.

La principal pregunta que plantea el texto en su visión general es: ¿ Cómo conectar marcas y personas en un mundo saturado de información?. Los investigadores, docentes en universidades españolas, unen planteamientos con directores creativos, directores y productores de contenidos, productores ejecutivos, directores de servicio al cliente y directores de marca de empresas y agencias publicitarias españolas, para ofrecer un abanico integral de las posibilidades en un mundo posdigital.

Juan Benavides Delgado, catedrático de Comunicación Audiovisual y Publicidad de la Universidad Complutense de Madrid, subraya en el prólogo, la importancia de la evolución de los intangibles que conforman la creación de contenidos en una marca, al mismo tiempo que sitúa a la construcción de conceptos y análisis útiles en un puesto muy relevante en el contexto actual:

Nos faltan todavía conceptos y no es fácil distinguir lo que es de lo que no es, pero nos dice que es. Todo parece revuelto y turbio. Pero ahí radica el mérito de este trabajo, que me recuerda también el atractivo que tenía la publicidad hace cincuenta o sesenta años cuando se abrieron las facultades universitarias: un mundo confuso y turbio, pero, al tiempo, de un enorme interés (Olivares y Gago, 2021: 21).

Seguido de esta aportación académica, Pablo Muñoz, Vicepresidente ejecutivo de BCMA (Branded Content Marketing Asociation), desarrolla una introducción que invita a pensar el concepto de lo que llama activos de comunicación producidos y coproducidos por las marcas.

Muñoz, además reflexiona sobre lo difícil que es definir el Branded Content, "es como tratar de definir el amor" comenta y apuesta por poner en contraposición el concepto sobre otros para definirlo: El Branded Content NO es Publicidad. El Branded Content NO es emplazamiento o integración del producto ("product placement"). El Branded Content NO es patrocinio. El Branded Content NO es publicidad nativa ("native advertising") (Olivares y Gago, 2021: 26).

En la primera parte del libro, llamada "Estructuras, metodologías y aplicaciones del Branded Content", se agrupan las investigaciones que refieren temas como la transformación digital y las nuevas fórmulas que se aplican en la creación de contenidos; la estrategia de contenidos y la consecución de los objetivos de marketing; la articulación creativa de los contenidos de marca; el branded podcast como herramienta de marca corporativa; la activación y producción de eventos en la generación de los contenidos de marca; el branded content en la ficción audiovisual; las estructuras de distribución y difusión de contenidos de marca, para finalizar con las funciones, formación y competencias del profesional de este sector.

En su segunda parte, el texto se enfoca a "Buenas prácticas y casos de éxito en España". Se analizan a fondo las acciones de comunicación ligadas a la creación de contenidos por parte de la empresa Ecoembes, como ejemplo de marca sin ánimos de lucro, Chocolates Trapa como plataforma de activismo de marca, la transformación social desde los contenidos de BBVA y las relaciones entre marcas y personas con el caso de Vodafone Yu.

Si tomamos en cuenta el interés de los españoles en el Branded Content y su potencial frente a la publicidad tradicional, tanto en formato audiovisual como sonoro, resalta que la estrategia conecta emocionalmente con mayor intensidad, al tiempo que sorprende, interesa, gusta y aporta mayor credibilidad a las marcas (BCMA y Sociograph, 2021).

En cada uno de los capítulos del libro, queda en evidencia la vigencia de las estrategias de creación de contenidos frente a la pérdida de la eficacia de la publicidad tradicional, debido a los factores que tienen que ver con la multicanalidad, la fragmentación de la audiencia en dichos canales, la saturación y la hiperconexión de consumidores que pasaron de pasivos a activos (Baraybar-Fernández, et al., 2017). 
La perspectiva compartida, academia - empresa, abre las puertas a nuevos planteamientos que busca consolidar las estrategias de creación y distribución de contenidos, desde el consenso, el correcto entendimiento del concepto y el profundo análisis del Branded Content como estrategia de comunicación intangible.

\section{Referencias bibliográficas}

[1] Baraybar-Fernández, A., Baños-González, M., Barquero-Pérez, O., Goya-Esteban, R., y de-laMorena-Gómez, A. (2017). Evaluation of emotional responses to television advertising through neuromarketing. [Evaluación de las respuestas emocionales a la publicidad televisiva desde el Neuromarketing]. Comunicar, 52, 19-28. https://doi.org/f5v5

[2] Branded Content Marketing Asociation y Sociograph (2021). Estudio Sociograph https://tinyurl.com/2p949y6e

[3] IAB (2021). I Estudio de Branded Content. https://tinyurl.com/55wbffnr

[4] Infoadex (2021). Estudio de la Inversión Publicitaria en España en 2020. https://tinyurl.com/29ew28he

[5] Olivares-Santamarina, J. y Gago-Gelado, R. (2021). El Branded Content en la comunicación posdigital: estructuras, aplicaciones y casos de éxito. Valencia: Tirant lo Blanch. 
